ORIGINAL ARTICLE

\title{
Prevalence and healthcare burden of illegal drug use among emergency department patients
}

\author{
S Binks, R Hoskins, D Salmon, J Benger
}

See end of article for authors' affiliations

.....................

Correspondence to: Dr J Benger, Faculty of Health and Social Care, University of the West of England, Bristol Glenside Campus, Blackberry Hill, Bristol, BS16 1DD; jonathan.benger@ubht. swest.nhs.uk

Accepted for publication 21 February 2005
Objectives: Illegal drug use is common in emergency department (ED) patients, but previous prevalence studies have relied upon approaches that may underestimate the true extent of the problem. The aim of this study was to examine illegal drug use in a typical adult ED.

Methods: We employed an independent researcher to prospectively and anonymously interview patients attending an inner city adult ED throughout all 168 hours of a typical week. Additional information collected from the treating clinician indicated whether each presentation was directly or indirectly related to illegal drug use.

Results: We found that $6.9 \%$ of all patient attendances were directly or indirectly related to illegal drug use, and hospital admission was required in nearly half of these. The majority of drug related problems were acute injuries, overdose, and the medical complications of drug use.

Conclusions: This suggests that the emergency healthcare burden related to illegal drug use is substantial, and higher than previously reported.
1 llegal drug use is common. The British Crime Survey 2000, a representative household survey of 13300 people, found that $34 \%$ of people aged $16-59$ years had used illegal drugs at some time, and $6 \%$ in the previous month. ${ }^{1}$

Health problems related to illegal drugs use are well recognised, but are difficult to quantify, as social circumstances make drug users difficult to identify and engage in research. In emergency care, studies of the prevalence of illegal drug use have relied on data collected by treating healthcare professionals, or retrospective review of the clinical notes. ${ }^{2-4}$ These methods may lead to bias and under-reporting.

Our study used an independent researcher to prospectively measure the proportion of illegal drug users among all patients attending an inner city emergency department (ED), and quantified the emergency healthcare burden represented by this patient group.

\section{METHODS}

The study was approved by Weston local research ethics committee. An independent researcher approached all adult patients attending our inner city ED, and with their consent, completed a confidential semi-structured survey. Patients were excluded if they had a life threatening illness, chronic mental impairment, were unable to understand/give verbal consent, or did not speak English. A technique of representative sampling was used, so that patients were recruited throughout all 168 hours of a typical week. Patients were anonymised, and responses were not shared with clinical staff. The researcher subsequently interviewed the treating doctor regarding the patient's diagnosis, need for admission, and whether they considered the attendance to be directly, indirectly, or not related to illegal drug use. Data were analysed using descriptive statistics and frequencies.

\section{RESULTS}

The results are summarised in fig 1 . The mean age was 40.4 years (range 16-98). Of the patients interviewed, 290 $(36.2 \%)$ had used illegal drugs in their lifetime (lifetime drug users), $129(16.1 \%)$ in the previous month, and $79(9.9 \%)$ within the previous 24 hours. In their lifetime, 46 patients $(5.7 \%)$ had injected drugs.

Of the 55 patients whose attendance was thought to be directly or indirectly related to drug use, 23 required admission to hospital. This represents $2.9 \%$ of all those responding. The commonest diagnoses directly related to illegal drug use were deliberate self harm/psychiatric (11/24 patients) and acute medical conditions such as cellulitis, chest pain, and deep venous thrombosis (12/24 patients).

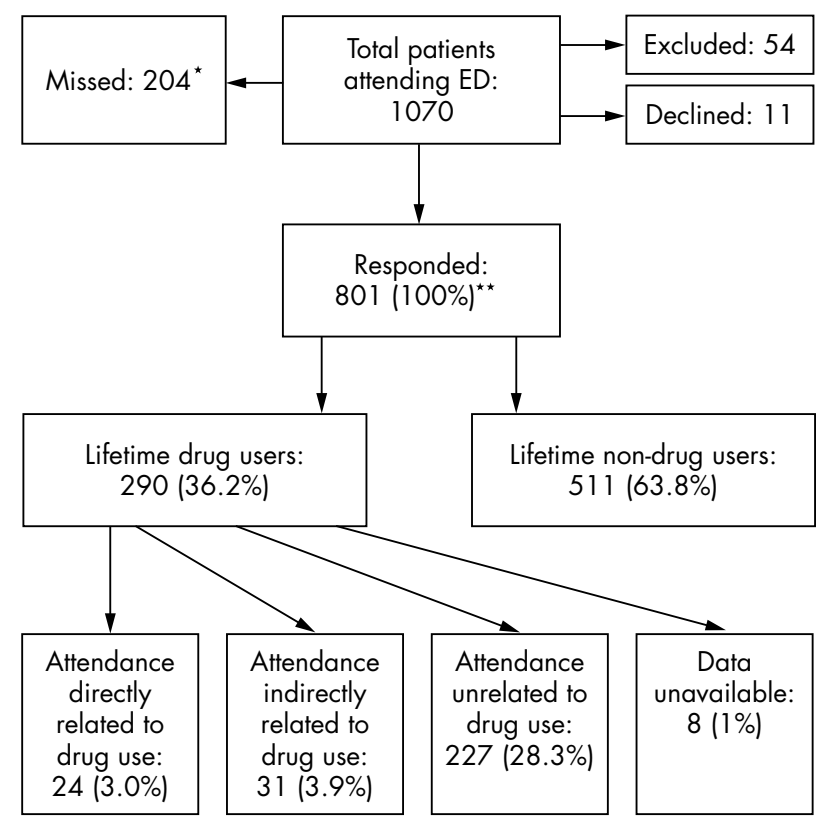

Figure 1 Flow diagram summarising the prevalence of illegal drug use, and related ED attendances. *204 patients were not approached during busy periods due to the practical limitations of a single researcher. Some of these patients left soon after arrival and did not wait to be seen by clinical staff. **All percentages are quoted in relation to the 801 patients who responded to the survey. 
The commonest diagnosis indirectly related to illegal drug use was assault/head injury (15/31 patients).

\section{DISCUSSION}

This study shows that $3.0 \%$ of all patient attendances to our inner-city emergency department are directly related, and $3.9 \%$ indirectly related, to illegal drug use. Hospital admission is required for nearly half of these patients. The majority of drug related problems are acute injuries (often assault), overdose, and the medical complications of drug use.

Our finding that $36.2 \%$ of patients are lifetime drug users is similar to the British Crime Survey estimate of $34 \% .{ }^{1}$ However, drug use within the past month was much higher in our study $(16.1 \% \vee 6 \%)$, suggesting that recent or current drug use creates an increased demand for emergency care.

To our knowledge, this study is the first to interview all ED patients, rather than a selected population, and the prospective collection of anonymised data by an independent researcher reduced the rate of non-disclosure and patient refusal. By excluding critically ill patients, it is possible that we have underestimated the prevalence of life threatening, drug related problems.

We believe that our results are representative of UK inner city EDs, but it is difficult to extrapolate to a wider patient population. Nevertheless, with annual ED attendances currently exceeding 14 million in England alone, ${ }^{5}$ it is possible that illegal drugs contribute directly or indirectly to 1 million ED attendances and 400000 acute hospital admissions in England each year.

\section{ACKNOWLDGEMENTS}

Our thanks go to $\mathrm{H}$ Moody for her skilled work in collecting the survey data, and to the staff of the Bristol Royal Infirmary Emergency Department for their assistance throughout the study.

\section{Authors' affiliations}

S Binks, R Hoskins, J Benger, Academic Department of Emergency

Care, Emergency Department, Bristol Royal Infirmary, Bristol, UK

D Salmon, J Benger, Faculty of Health and Social Care, University of the West of England, Bristol Glenside Campus, Blackberry Hill, Bristol, UK

This research was funded by the Clinical and Health Services Network at the Faculty of Health \& Social Care, University of the West of England, Bristol, UK, and was carried out independently of the funding source.

Competing interests: none declared

\section{REFERENCES}

1 Ramsay M, Baker P, Goulden C, et al. Drug misuse declared in 2000: results from the British Crime Survey, Home Office Research Study 224. London: Home Office Research, 2001.

2 Stone MH, Stone DH, MacGreggor HAR. Intravenous drug misusers presenting to the Accident and Emergency department of a large teaching hospital. A failure of clinical management? Scott Med J 1989;34:428-30.

3 Makower RM, Pennycook AG, Moulton C. Intravenous drug abusers attending an inner city Accident and Emergency department. Arch Emerg Med 1992;9:32-9

4 Gibbs T, Ross L. Illicit drug use related attendances at Accident and Emergency services in Aberdeen: A prospective six month survey. Health Bull 2000;58:170-5.

5 Department of Health. Hospital activity statistics. www.performance.doh.gov.uk/hospitalactivity/statistics/2000-01/ a_and_e_attendances/y00.htm. Accessed 22 September, 2004. 